Table 2 Case log/Objective Structured Clinical Examination correlations

$\begin{array}{llll} & \text { History } & \text { Physical examination } & \text { Clinical formulation } \\ \text { Pearson correlation } & 0.029 & 0.063 & 0.172^{\mathrm{a}} \\ \text { Significance (2-tailed) } & 0.560 & 0.211 & 0.001^{\mathrm{a}}\end{array}$

Correlations between cases logged per student and scores on the history, physical examination, and clinical formulation components of the Objective Structured Clinical Examination.

${ }^{a}$ Correlation is significant at the 0.01 level (2-tailed).

of neurologic conditions including behavioral problems, infections, congenital abnormalities, and psychogenic symptoms, and neuro-oncology ( $\mathrm{n}=1,608$ cases). The least frequently encountered categories were dementia $(\mathrm{n}=164)$ and other neurodegenerative disorders $(\mathrm{n}=276)$.

The mean NBME score for all students was 77.77 (range 55-99). A significant relationship was demonstrated between number of patients recorded via case logs and NBME subject examination scores $(r=$ $0.142, p=0.05)$. The mean NBME subject examination score in the cohort of students logging the

\section{Comment: \\ Making a case for seeing more cases but not a case for more case logs}

Albert et al. ${ }^{1}$ examined the relationship between number of cases encountered by medical students in a 1-week outpatient component of a 4-week neurology clerkship and performance on the National Board of Medical Examiners Neurology Subject Examination and an objective standardized clinical examination (OSCE). They found a significant correlation between the number of outpatients logged and scores on the subject test and written component of the OSCE. These findings contrast with those of Poisson et al., ${ }^{2}$ who found no correlation between number of patients logged and final clerkship performance or total written examination scores, and a negative correlation between number of patients seen in diagnostic categories and test disease category subscores.

A few distinctions between these studies might explain these differences, including a more standardized examination and larger patient volume in the current study, where the average number of outpatients logged per student in 1 week was 24.8, compared to 17 in the 4-week clerkship in the previous study. It is tempting to speculate that there may be a threshold number of patients seen before clinical experience outweighs other forms of clerkship learning.

The current study is from a single medical school and only assessed patient experience from one clerkship component. Further multicenter studies are needed to confirm that more-and what kind of-patient encounters are better regarding knowledge and skills gained in a neurology clerkship. Finally, both this study and the study by Poisson et al. used patient logs as a measure of patient encounters; though each came to different conclusions about their effectiveness, neither used a control group without case logs. Even if the intuitive findings from the current study hold up, future studies should also assess whether the specific, time-consuming act of logging patients has any intrinsic value, or lack thereof, in educational outcome.

1. Albert DV, Brorson JR, Amidei C, Lukas RV. Case logs in the assessment of medical students in the neurology outpatient clinic. Neurology 2014;82:e138-e141.

2. Poisson SN, Gelb DJ, Oh MFS, Gruppen LD. Experience may not be the best teacher: patient logs do not correlate with clerkship performance. Neurology 2009; 72:699-704

Steven L. Lewis, MD

From the Department of Neurological Sciences, Rush University Medical Center, Chicago, IL.

Study funding: No targeted funding reported.

Disclosure: S. Lewis receives a stipend in his editorial capacity for Neurology ${ }^{\circledR}$ and as Editor for

Continuum: Lifelong Learning in Neurology ${ }^{\circledR}$, and has received royalties for book authorship and editorship from Wolters Kluwer and Wiley-Blackwell. lowest quartile of cases (6-21 cases) was 76.23, the second quartile (22-26 cases) was 77.61 , the third quartile (27-29 cases) was 78.78 , and the fourth quartile (30-34 cases) was 78.61. Thus, a difference of 2.38 points on the mean NBME subject examination score exists between the lowest case logging quartile and the highest. This 2.38-point difference in average absolute NBME score between students seeing fewer vs greater cases in the outpatient clinic corresponds to a difference of about 10 percentile points in the score distributions reported by the NBME, representing a modest but considerable improvement in student performance. A similar relationship was also found with regards to number of cases recorded and OSCE scores $(r=0.136, p=0.007)$. When evaluating the relationship between patients recorded per student via case logs and scores on 3 distinct components of the OSCE, a correlation was found only on the faculty-graded clinical written formulation component $(r=0.172, p=0.001)$ (table 2).

DISCUSSION We present evaluations of correlations in medical students between patient encounters documented via case logs and performance on national standardized examinations of knowledge and validated examinations of clinical skill in a specialty. Outpatient clinical experiences occurred either at an academic medical center or a community medical center, making findings relevant to a range of clinical education settings. While these findings specifically reflect our analyses of medical students in a neurology clerkship, it would be reasonable to hypothesize that similar relationships between volume of cases seen and performance on standardized examinations of knowledge and clinical skill would be present in other medical student clerkships and non-procedure-oriented residency/fellowship programs. Of particular interest is that the correlation between number of cases recorded per student and performance on the OSCE was due exclusively to performance on the written clinical formulation component of the evaluation, reflecting students' skills in reporting and analyzing clinical findings. There was no relationship between case volume and the components of the OSCE that evaluate thoroughness of history taking and physical examination. We hypothesize that by directly observing expert clinicians evaluating patients with a wide range of complaints and underlying pathologies, trainees gain valuable experience in formulating their own thoughts and developing management plans with respect to clinical encounters. By understanding the correlations between volume of patients encountered and students' outcomes on specific performance measures, we can work on tailoring the outpatient experience to best achieve our educational goals. As the outpatient experience represents only a single component of a 


\title{
Neurology
}

\author{
Comment: Making a case for seeing more cases but not a case for more case logs \\ Steven L. Lewis \\ Neurology 2014;82;e140 \\ DOI 10.1212/WNL.0000000000000346
}

This information is current as of April 21, 2014

Updated Information \&
Services

References

Subspecialty Collections

Permissions \& Licensing

Reprints including high resolution figures, can be found at: http://n.neurology.org/content/82/16/e140.full

This article cites 2 articles, 2 of which you can access for free at: http://n.neurology.org/content/82/16/e140.full\#ref-list-1

This article, along with others on similar topics, appears in the following collection(s):

Clinical neurology examination

http://n.neurology.org/cgi/collection/clinical_neurology_examination

Information about reproducing this article in parts (figures,tables) or in its entirety can be found online at:

http://www.neurology.org/about/about_the_journal\#permissions

Information about ordering reprints can be found online:

http://n.neurology.org/subscribers/advertise

Neurology ${ }^{\circledR}$ is the official journal of the American Academy of Neurology. Published continuously since 1951, it is now a weekly with 48 issues per year. Copyright (O 2014 American Academy of Neurology. All rights reserved. Print ISSN: 0028-3878. Online ISSN: 1526-632X.

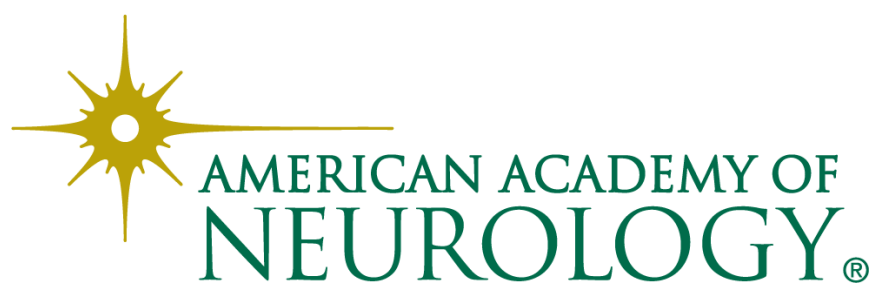

